\title{
Preparation of chitin-amphipathic anion/ quaternary ammonium salt ecofriendly dressing and its effect on wound healing in mice
}

This article was published in the following Dove Press journal: International Journal of Nanomedicine

\author{
Daijun Zhoul-3 \\ Ruijia Yang ${ }^{4}$ \\ Tao Yang ${ }^{1-3}$ \\ Malcolm Xing ${ }^{1-4}$ \\ Gaoxing Luo ${ }^{1-3}$
}

'Institute of Burn Research, ${ }^{2}$ State Key Laboratory of Trauma, Burn and Combined Injury, ${ }^{3}$ Key Laboratory of Proteomics of Chongqing, Southwest Hospital, Army Medical University (Third Military Medical University), Chongqing, China; ${ }^{4}$ Department of Mechanical Engineering, University of Manitoba, Winnipeg, MB, Canada

Correspondence: Gaoxing Luo; Malcolm Xing Institute of Burn Research, Southwest Hospital, Third Military Medical University, 30 Gaotanyan Main Street, Shapingba District, Chongqing 400038, China

Tel/fax +862368975399

Email logxw@yahoo.com; nanoxing@gmail.com
Objective: This study aimed to prepare an eco-friendly dressing using a chitin-derived membrane with amphipathic anion/quaternary ammonium salt designed for antibacterial purposes. Methods: Four dressings were prepared and group A was chitin, group B was chitin + amphiphilic ion, group $\mathrm{C}$ was chitin + quaternary ammonium salt, group D was chitin + amphiphilic ion + quaternary ammonium salt.

Results: In the group D material, precipitation of adherent composite ions was observed. The contact angle test showed that the material was hydrophilic. The drug loading rate in groups B, C, and D was 40-50 (ug:mg), the entrapment efficiency was 70\%-75\% $(P>0.05)$, and the cumulative release percentages were $87.3 \%, 88.7 \%$, and $90.2 \%$ after $72 \mathrm{~h}$ for group $\mathrm{B}, \mathrm{C}$, and $\mathrm{D}$, respectively. The anti-bacterial activity in vitro was in the order $\mathrm{D}>\mathrm{C}>\mathrm{B}>\mathrm{A}>$ control $(P>0.05)$. The anti-pollution activity in vitro was in the order $\mathrm{D}>\mathrm{B}>\mathrm{C}>\mathrm{A}(P<0.05)$. The cell proliferation inhibition test showed slight proliferation inhibition $(P<0.05)$ only on the seventh day for group $\mathrm{D}$. Seven days after injury, the wound healing rate was in the order $\mathrm{D}>\mathrm{C}>$ commercial chitin dressing $>\mathrm{B}>\mathrm{A}>\operatorname{control}(P<0.05)$, and the length of the neonatal epithelium also showed the same trend. Additionally, PCNA and CD31 expression indicated that cell proliferation and angiogenesis were enhanced when skin defects were covered with the D group material $(P<0.05)$.

Conclusion: chitin-amphiphilic ion/quaternary ammonium salt dressing was successfully prepared. The antibacterial and antipollution effects of the prepared material (group D) were both very good, acting to promote wound healing.

Keywords: chitin, amphipathic anion, quaternary ammonium salt, wound healing, anti-infective dressing

\section{Introduction}

Chitin is a natural polysaccharide made of $N$-acetyl-2-amino-2-deoxy-D-glucose linked through 13-14 glycosidic linkages. As a natural biopolymer, chitin is widely found in the shell of lower animals, especially crustaceans, and in the cell wall of lower plants, bacteria, and algae. The overall production of chitin is only second to cellulose in nature. ${ }^{1}$ Chitin is widely used in the medical field, with good biocompatibility, no toxicity, low cost, easy modification, good mechanical strength, and broad-spectrum antibacterial activity. ${ }^{2}$ For example, it can be used as components of medical biomaterials, such as absorbent surgical sutures, hemostatic agents, immune promoters, tumor inhibitors, and healing agents. ${ }^{3,4}$ In their study on novel chitin/chitosan-glucan wound dressing, Abdel-Mohsen et al reported that novel nonwoven microfiber mats were fabricated by wet-dry spinning technique and evaluated the mechanical properties of fabrics mats 
and surface morphology. The novel chitin/chitosan-glucan complex(ChCsGC) nonwovens exhibited excellent surgical wound healing ability when tested using rat models. ${ }^{5}$ Also, uniformly sized silver/chitosan- $O$-methoxy polyethylene glycol core shell nanoparticles with different degrees of substitution were synthesized. Experimental results revealed that the prepared silver core particles had the size of $1,802 \pm 2,202 \mathrm{~nm}$. Core shell structure with chitosan- $O$-methoxy polyethylene glycol coating had the size of 4,002 $\pm 2,202 \mathrm{~nm} .{ }^{6}$ However, there are regular ring structures and strong hydrogen bonds among chitin molecules, resulting in high crystallinity and poor solubility in water, dilute alkali, dilute acid, and general organic solvents, which greatly limit more widespread application. To overcome these shortcomings, chitin can be prepared as quaternized ammonium salt, allowing chemical modification. ${ }^{7,8}$

Chitin quaternary ammonium salt offers improved solubility and biocompatibility in addition to the qualities of no toxicity and easy and inexpensive preparation. As a commonly used bactericide, the polymerization of quaternary ammonium salt and chitosan derived from chitin has been well studied. ${ }^{9,10}$ A series of water-soluble chitosan derivatives with hydrophilic quaternary ammonium salt groups not only maintained the properties of chitosan, such as antibacterial film formation, flocculation, and biodegradability, but also exhibited better water solubility, stronger positive charge, and wider $\mathrm{pH}$ value than chitosan. ${ }^{9,11}$ Amphiphilic ions are hydrophilic and lipophilic, with good antipollution effect, and have been initially applied in the field of wound dressings. ${ }^{12,13}$

Therefore, the study of chitin and quaternary ammonium salts/amphiphilic ions have become a hot field of research because of not only the wide range of potential applications and environmental protection of natural chitin sources but also the antibacterial effects of quaternary ammonium salts and the antipollution effects of amphiphilic ions. Here, we prepared a chitin-amphipathic anion/quaternary ammonium salt ecofriendly dressing and studied its antibacterial activity in vitro and effects on wound healing in mice. These results provide reference for a further study of natural dressings.

\section{Materials and methods Ethical statement}

BALB/c mice (male, weighing approximately $25 \mathrm{~g}$ ) were purchased from the Experimental Animal Department of the Army Medical University. The animals were individually raised in plastic cages under standardized conditions (room temperature, $25^{\circ} \mathrm{C}$; relative humidity, $50 \%$; circadian rhythm, $12 \mathrm{~h}$ ). The animal experiments were approved by the animal ethics committee of the Army Medical University. All experiments were conducted in accordance with the relevant ethical requirements of the laboratory animal ethics committee of the Army Medical University. A schematic of the methods is illustrated in Figure 1.
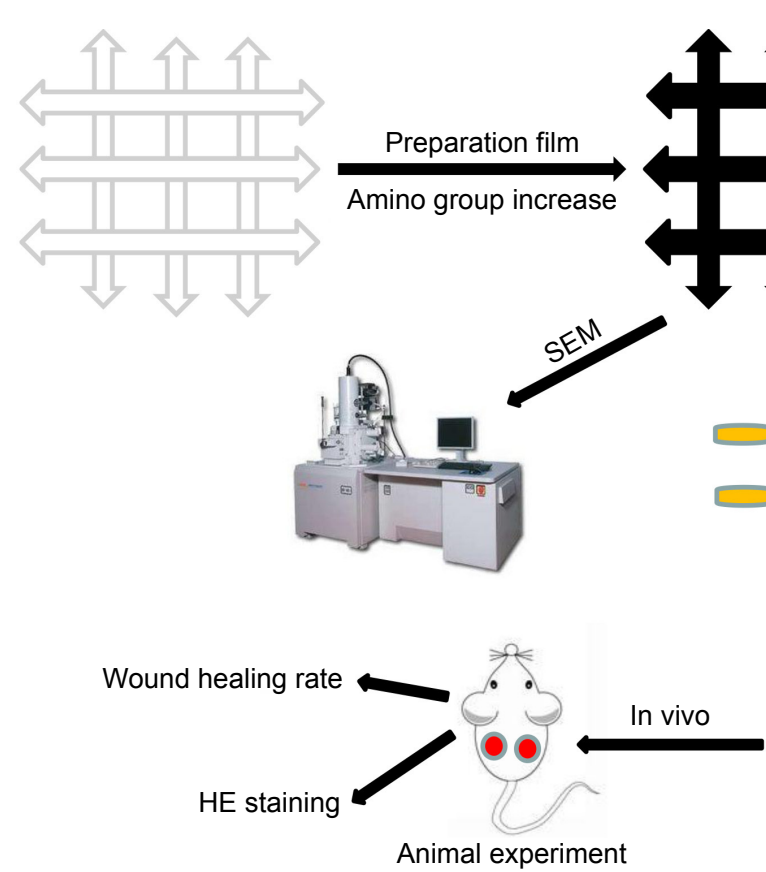

Shell surface

1 Chitin QA salt

Fibroblast
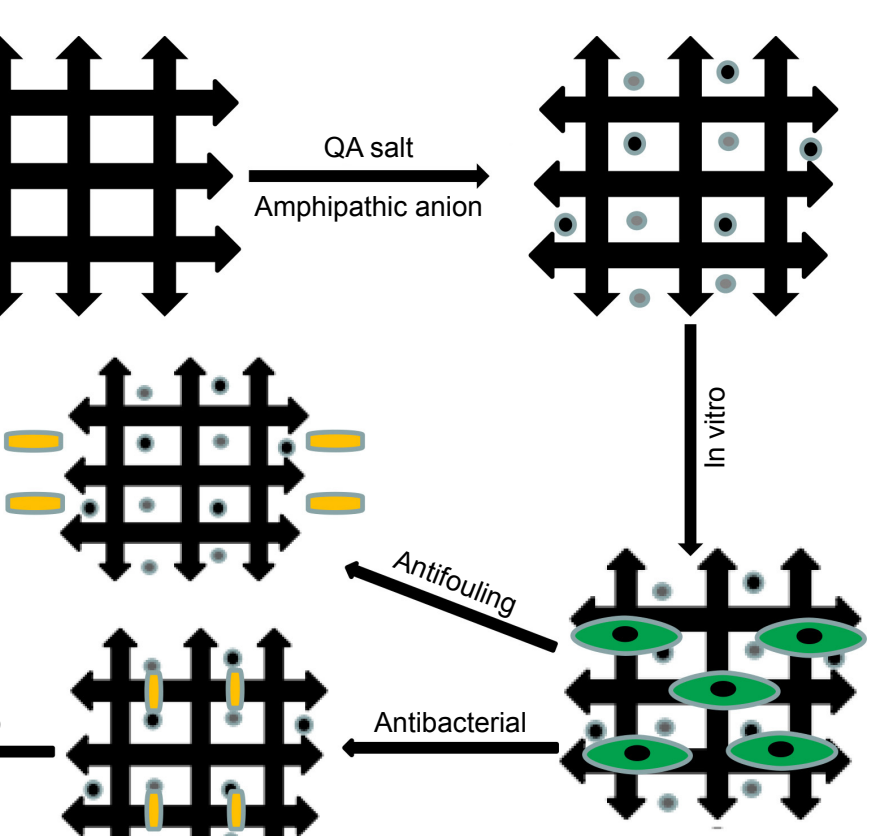

Cytotoxicity assessment

Figure I Schematic of chitin-amphipathic anion/QA salt preparation and functional evaluation process.

Abbreviations: HE, hematoxylin-eosin staining; QA, quaternary ammonium; SEM, scanning electron microscopy. 


\section{Preparation of materials}

All chemical reagents were purchased from Sigma-Aldrich Co. (St Louis, MO, USA), including Mussel, $\mathrm{HCl}, \mathrm{NaOH}$, (3-aminopropyl)trimethoxysilane (APMS), ethyl alcohol, acidic acid, 2-(dodecylsulfanylthiocarbonylsulfanyl)2-methylpropionic acid, 1-(3-dimethylaminopropyl)-3ethylcarbodiimide hydrochloride, $\mathrm{N}, \mathrm{N}$-dimethylformamide (DMF), $N$-(2-(acryloyloxy) ethyl)- $N, N$-dimethyl, hexyl bromide, methyl cyanide, azobisisobutyronitrile (AIBN), and 2,2,3,3,4,4,4-heptafluorobutyl acrylate, 97\%.

\section{Preparation of mussel shell surface with chitosan film}

Mussel shells were immersed into $5 \% \mathrm{HCl}$ solution for 3 days (the composition of mussel shells: dibutyltin, $1.54 \pm 0.12 \mathrm{mg} / \mathrm{kg}$, monobutyltin, $1.50 \pm 0.28 \mathrm{mg} / \mathrm{kg}$, tributyltin, $2.2 \pm 0.19 \mathrm{mg} / \mathrm{kg}$; shipped in wet ice; storage temperature: $-20^{\circ} \mathrm{C}$ ).

\section{Synthesis of antibacterial monomers}

The antibacterial monomer used was $N$-(2-(acryloyloxy) ethyl)- $N, N$-dimethylhexanyl-1-ammonium, synthesized from reaction of $N$-(2-(acryloyloxy) ethyl)- $N, N$-dimethyl and hexyl bromide. First, $1 \mathrm{~g} N$-(2-(acryloyloxy) ethyl)- $N, N$ dimethyl was dissolved in methyl cyanide to a concentration of $15 \%$. Then, hexyl bromide was added into the solution (molar ratio of $\mathrm{N}$-(2-(acryloyloxy) ethyl)- $\mathrm{N}, \mathrm{N}$-dimethyl:hexyl bromide $=1: 1.2$ ), and the mixture was reacted at $80^{\circ} \mathrm{C}$ for $16 \mathrm{~h}$ under vigorous stirring. After the reaction was completed, the mixture was filtered by vacuum filtration and, eventually, a white solid (A) was obtained after lyophilization.

\section{Increase in amino groups on the surface of shells}

By immersing mussel shells into base, we can obtain chitosan with $\mathrm{NH} 2$ - groups; but as the number of $\mathrm{NH} 2$ - groups can be variable and it significantly influences the following procedures, we increased the number of $\mathrm{NH} 2$ - groups by APMS modification of the surface. To do this, $0.3 \mathrm{~mL}$ APMS was added into $0.6 \mathrm{~mL}$ dilute acidic acid $(10 \%, \mathrm{v} / \mathrm{v})$ and $10 \mathrm{~mL}$ ethyl alcohol. Then, mussel shells were immersed into the mixture and soaked for $15 \mathrm{~min}$. Water was used to wash the shell 15 times, and then the shells were lyophilized.

\section{Preparation of antibacterial surfaces}

Reversible addition-fragmentation chain transfer (RAFT) was used to prepare both antibacterial and antifouling surfaces. First, $N$-(2-(acryloyloxy) ethyl)- $N, N$-dimethyl (RAFT reagent) was added onto the surface by the reaction of $\mathrm{COOH}-$ and NH2- groups, then through RAFT to add antibacterial and antifouling molecules onto the surfaces. Next, $10 \mathrm{~mL}$ of DMF, $36.4 \mathrm{~g}$ RAFT reagent, and $28.7 \mathrm{~g}$ 1-(3-dimethylaminopropyl)-3-ethylcarbodiimide hydrochloride were added into a $20-\mathrm{mL}$ beaker. The shells were then immersed into the mixture and soaked for 3 days. Next, DMF and water were used to wash the shells, and then, the shells were lyophilized to obtain RAFT-shell (B). Quaternary ammonium salt has demonstrated antibacterial property, so $\mathrm{NH} 4+$ structure was used to modify surfaces. Material B was then immersed into a solution of $10 \mathrm{~mL}$ DMF, $0.2 \mathrm{~g} \mathrm{~A}$, and $10 \mathrm{mg}$ AIBN; N2 was used to degas the mixture for $20 \mathrm{~min}$, and then, the reaction mixture was incubated at $60^{\circ} \mathrm{C}$ overnight. After completion of the reaction, DMF and water were used to wash the shells before lyophilization to obtain $\mathrm{C}$.

\section{Preparation of antifouling surfaces}

A molecule with CF3- structure was required to confer the antifouling property. For this, A was immersed into a solution of $10 \mathrm{~mL}$ DMF, $0.2 \mathrm{~g}$ 2,2,3,3,4,4,4-heptafluorobutyl acrylate, and $10 \mathrm{mg}$ AIBN. N2 was used to degas the mixture for $20 \mathrm{~min}$, and the reaction mixture was incubated at $60^{\circ} \mathrm{C}$ overnight. After completion, DMF and water were used to wash the shells before lyophilization to obtain D.

\section{Preparation of antibacterial-antifouling surfaces}

The preparation of surfaces with both antibacterial and antifouling properties combines the above two protocols. For achieving this, $\mathrm{C}$ was immersed into a solution of $10 \mathrm{~mL}$ DMF, 0.2 g 2,2,3,3,4,4,4-heptafluorobutyl acrylate, and $10 \mathrm{mg}$ AIBN. N2 was used to degas the mixture for $20 \mathrm{~min}$, and the reaction mixture was incubated at $60^{\circ} \mathrm{C}$ overnight. After completion, DMF and water were used to wash the shells before lyophilization to obtain $\mathrm{E}$.

\section{Scanning electron microscopy (SEM)}

The material wafers were carefully washed with deionized water, dried, and sprayed, and the aperture structures of the films were observed under vacuum condition by a SEM and photographed.

\section{Contact angle test}

The film of different materials was placed on a horizontal surface, and $1 \mu \mathrm{L}$ deionized water was dripped from the top to the surface of the material. The contact angle size of the droplet was measured, and the value of each sample was measured three times and averaged. 


\section{Drug loading and encapsulation efficiency Determination of standard curve}

A $50 \mathrm{mg}$ sample of the amphipathic anion/quaternary ammonium salt was weighed and dissolved in $5 \mathrm{~mL}$ PBS buffer for a final concentration of $10 \mathrm{mg} / \mathrm{mL}$. The PBS was diluted threefold (ie, $2.5,5,10 \mathrm{mg} / \mathrm{mL}$ ), and the absorbance of the amphipathic anion/quaternary ammonium salt solutions at different concentrations was measured at $450 \mathrm{~nm}$ with an ultraviolet spectrophotometer. The amphipathic anion/ quaternary ammonium salt concentration was used as the abscissa, the absorbance was plotted as the ordinate to draw a standard curve, and a linear regression equation was used.

\section{Determination of drug loading and encapsulation efficiency}

To test the efficiency of drug loading, $50 \mathrm{mg}$ samples from the $\mathrm{B}, \mathrm{C}$, and $\mathrm{D}$ groups were weighed and put into liquid nitrogen. The frozen powder was added to $5 \mathrm{~mL}$ PBS buffer and subjected to ultrasonic dispersion for $60 \mathrm{~min}$. The mixture was then centrifuged, and the supernatant was removed. The absorbance of the solution was measured at $450 \mathrm{~nm}$ with an ultraviolet spectrophotometer. A standard curve was generated and used to calculate the concentration and determine the entrapment efficiency and drug loading.

$$
\text { Drug loading }=\frac{\text { Actual concentration } \times \text { Volume }(\mu \mathrm{g})}{\text { Dissolved total mass }(\mathrm{mg})}
$$

and

$$
\text { Encapsulation efficiency }=\frac{\text { Actual concentration }}{\text { Theoretical concentration }}
$$

\section{Drug release in vitro}

First, $50 \mathrm{mg}$ of each material was weighed and added to $5 \mathrm{~mL}$ of PBS buffer, and then placed in a constant temperature shaking table $\left(37^{\circ} \mathrm{C} 70 \mathrm{r} / \mathrm{min}\right)$. At specific time points $(0.5,12,24$, 48,72 , or $96 \mathrm{~h}$ ), the tubes were removed. The upper $2 \mathrm{~mL}$ of released liquid was removed with a pipette and the absorbance was measured by UV spectrophotometer. Next, $2 \mathrm{~mL}$ of fresh PBS solution was added to the test tube to keep the total volume of the system unchanged. During the test, fresh PBS buffer solution was used in a cuvette as a control. According to the standard curve, the measured concentration was calculated, and the released amount in each period was calculated. Finally, the cumulative release amount was calculated.

\section{Bacterial co-culture}

Staphylococcus aureus and Escherichia coli were obtained from the Third Military Medical University Southwest
Hospital Institute of Burns. They were part of the routine hospital laboratory procedure. First, the bacteria were amplified (grown overnight) to $1 \times 10^{9}$ colony-forming units $(\mathrm{CFU}) / \mathrm{mL}$ and then diluted with Luria-Bertani medium to $1 \times 10^{4} \mathrm{CFU} / \mathrm{mL}$. The OD value (standard OD $=0.7$ ) of $100 \mathrm{~mL}$ bacterial fluid was detected by a microplate reader. Each sample was placed into three wells $(200 \mu \mathrm{L}$ per well). After incubation at $37^{\circ} \mathrm{C}$ for $24 \mathrm{~h}$, the change in OD values was determined. The operations were repeated three times.

\section{Quantitative counting experiment of adhesive bacterial culture}

S. aureus and E. coli were grown to $1 \times 10^{9} \mathrm{CFU} / \mathrm{mL}$ and then diluted to $1 \times 10^{4} \mathrm{CFU} / \mathrm{mL}$. Materials were sterilized with $75 \%$ alcohol at room temperature for $20 \mathrm{~min}$ and washed three times with PBS. Then, $200 \mu \mathrm{L}$ of diluted bacteria was added into the wells of a 96-well plate containing the membrane, which was rinsed once with PBS after incubation at $37^{\circ}$ for $1.5 \mathrm{~h}$. The membrane material was adhered to the bottom of the plate and flattened; then, $45^{\circ} \mathrm{C} \mathrm{LB}$ agar was poured into the plates, which were cultured at $37^{\circ} \mathrm{C}$ overnight after solidification. Finally, the plates were taken out, photographed, and counted. The operations were repeated three times.

\section{Assay of cytotoxicity}

Normal primary neonatal mice were used as a source of primary fibroblasts, which were used when cells were transferred to the second and third generations. The cells were counted, and the required amount was calculated at 2,000 cells per well using Dulbecco's Modified Eagle Medium in 96-well plates. Samples from each group of materials were placed into 12 parallel wells (measured four times, on Days 1, 3,5 , and 7). To each well, $150 \mu \mathrm{L}$ configured medium was added, and then, the plates were placed in an incubator at $37^{\circ} \mathrm{C}$. The operations were repeated three times.

\section{Mice full-thickness skin defect wound model}

One day before the experiment, mice were injected intraperitoneally with $1 \%$ pentobarbital sodium $(70 \mu \mathrm{L} / \mathrm{g})$ and grown separately in single cages. The next day, after the mouse was anesthetized on the back, two circular full-thickness skin defect wounds with a diameter of about $0.6 \mathrm{~cm}$ were prepared using a perforator on the lower part of the back, in front of the thigh, symmetrically on the right and left sides. The two kinds of bacteria were co-cultured (S. aureus and E. coli), and $5 \mu \mathrm{L}$ of $10^{8} / \mathrm{mL}$ culture was added into each wound hole. After disinfection with $75 \%$ alcohol and rinsing with PBS buffer to completely remove the alcohol, the prepared materials were 
applied to the wounds and fixed with an adhesive towel. The wounds were photographed on Days $0,1,3,5$, and 7 after injury and replaced with fresh material. Commercial chitin dressing (CCD) was used as the positive control, which was obtained from Shandong Beno Medical Biology Technology Co., Ltd (Qingdao, China; national invention patent number [ZL200620082586.1]).

\section{Rate of wound healing}

The wound healing rate can be calculated based on the original wound area and how it changes after the injury. This was measured using IPP6.0 software. The area of interest function was used to select the wound area, measuring its pixel area by "count size" and calculating the wound area.

The wound healing rate

The original wound area - The remaining

$$
=\frac{\text { wound area after injury }}{\text { Original wound area }} \times 100 \%
$$

\section{HE staining}

At 3 and 7 days post-injury, samples of the wound tissue were obtained, and paraffin sections were prepared. HE staining was performed according to conventional methods. The neonatal epithelial length was measured by different pathologists.

\section{Detection of PCNA and CD3I expression by Western blot}

We used Western blot to detect PCNA and CD31 on Day 7 postinjury. Briefly, full-thickness wound tissues, including newly regenerated epidermis and granulation tissues, were cut into $\sim 10 \times 10 \mathrm{~mm}^{2}$ size and placed into liquid nitrogen immediately after harvest. Then, lysis buffer (KeyGen, Beijing, China) was added to the samples after grinding. The samples were rotated for $15 \mathrm{~min}$ at $4^{\circ} \mathrm{C}$, followed by centrifugation at $14,000 \mathrm{rpm}$ for $15 \mathrm{~min}$. The supernatants were then collected, and the protein concentrations in the supernatants were examined by the bicinchoninic acid method according to the instructions of Varioskan Flash (Thermo Fisher Scientific, Waltham, MA, USA), prior to loading onto $8 \%$ sodium dodecyl sulfate-polyacrylamide gel electrophoresis gels. Then, $50 \mathrm{mg}$ protein samples were used for Western blot. Anti-CD31 antibody (ab28364, Abcam, Cambridge, UK), anti-PCNA antibody (ab15497, Abcam) and anti-tubulin antibody (Sungene, China) is diluted according to the proportion of the instructions, then overnight at $4^{\circ} \mathrm{C}$. The membrane was incubated with HRP-labeled goat antirabbit secondary antibody (Zhongshan Biology Company, Guangdong, China) at 1:2,000 dilution for $1 \mathrm{~h}$ at $25^{\circ} \mathrm{C}$. After incubation, the polyvinylidene difluoride membrane was washed with tris-buffered saline with Tween for five times and visualized by chemiluminescence (Thermo Fisher Scientific).

\section{Statistical analysis}

The significant difference between groups was analyzed by using one-way analysis of variance (for two groups) and twoway analysis of variance (for more than two groups) in the Origin software, and the experimental data are expressed as mean \pm SD. Statistical significance was accepted at $P<0.05$.

\section{Results}

\section{Electron microscopy scanning}

As shown in Figure 2, the chitin in group A retained the complete structure of the shell and membrane with a clear
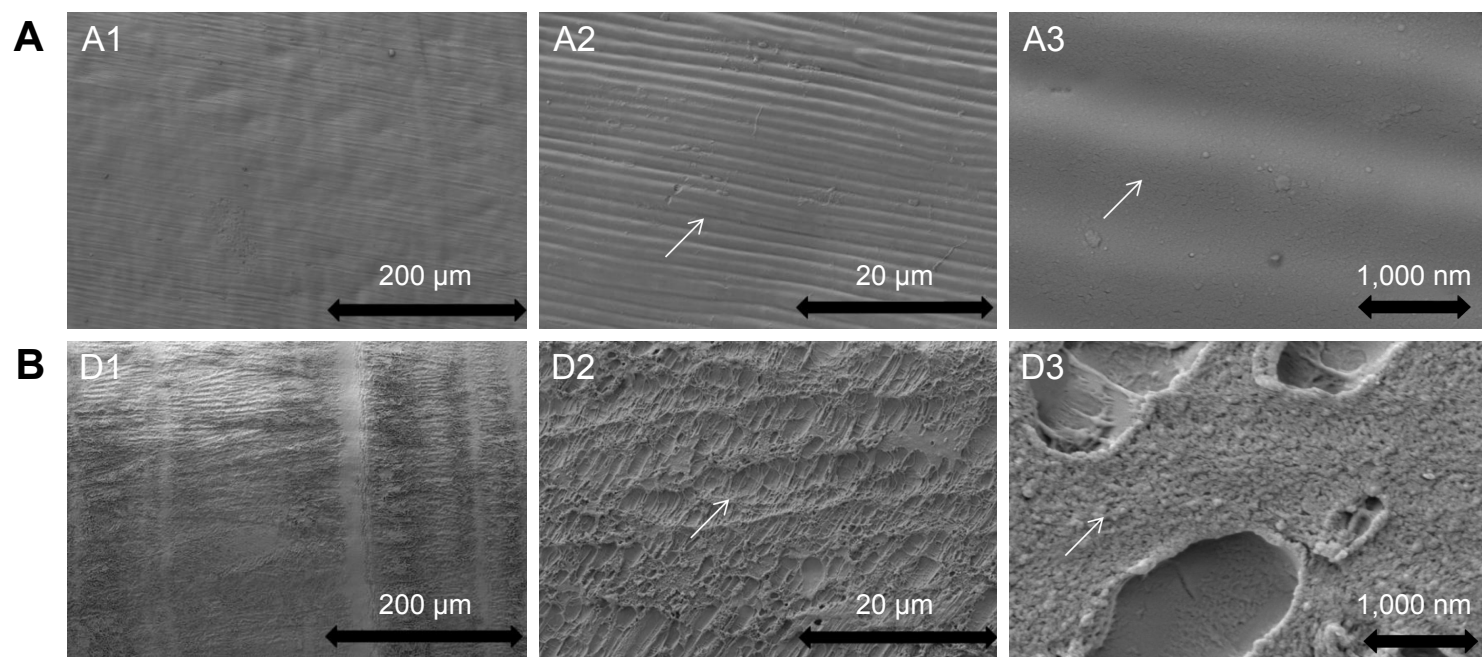

Figure 2 Representative SEM images of groups $A$ and $D$.

Notes: (A) AI-A3 chitin. (B) DI-D3 chitin-amphiphilic ion/quaternary ammonium salt. The white arrows are significantly different in structure.

Abbreviation: SEM, scanning electron microscopy. 
A

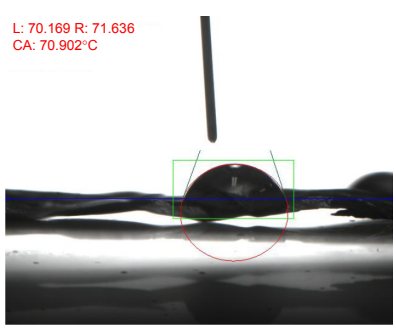

B

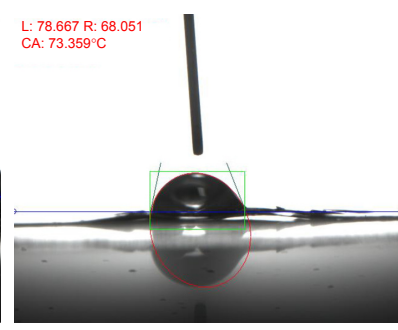

C

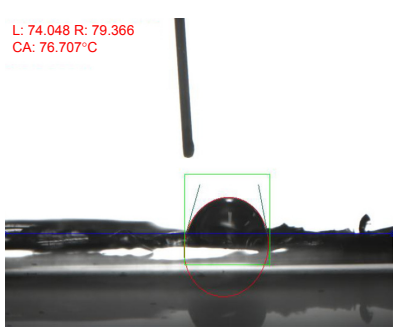

D

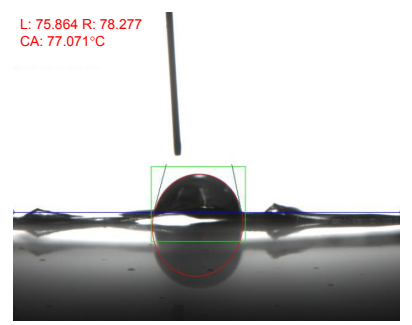

Figure 3 The contact angle (the angle between the blue and the green lines) of group A (chitin), group B (chitin + amphiphilic ion), group C (chitin + quaternary ammonium salt), and group $D$ (chitin + amphiphilic ion + quaternary ammonium salt).

Abbreviation: CA, contact angle.

texture under magnification. In the chitin-amphiphilic ion/ quaternary ammonium salt group, group D, the brush-like structure layer was visible under D1, rules and texture structure changed under D2, and precipitated and bedding amphiphilic ion/quaternary ammonium salt layer was visible under D3. The white arrows were significantly different in structure. The microsphere indicated by the arrow in D3 may be the amphipathic anion/quaternary ammonium salt with a diameter of hundreds of nanometers.

\section{Contact angle test}

As shown in Figure 3, the average contact angle $(\theta)$ of A was $69.86^{\circ} \pm 6.85^{\circ}$, B was $72.62^{\circ} \pm 7.05^{\circ}, \mathrm{C}$ was $74.38^{\circ} \pm 7.29^{\circ}$, and $\mathrm{D}$ was $78.03^{\circ} \pm 7.50^{\circ}$. There was no statistically significant difference among the four groups $(P>0.05)$.

\section{Enzyme loading and encapsulation efficiency and release in vitro}

As shown in Figure 4, the drug loading rates for the materials from groups B, C, and D were 40-50 $\mu \mathrm{g}: \mathrm{mg}$, and the entrapment efficiency was $70 \%-75 \%$. There was no difference between groups $(P>0.05)$. The release rate of the three groups was stable and maximum at $72 \mathrm{~h}$. The cumulative release percentages were $87.3 \%, 88.7 \%$, and $90.2 \%$ after $72 \mathrm{~h}$ in groups $\mathrm{B}, \mathrm{C}$, and $\mathrm{D}$, respectively.

\section{Assay of antibacterial activity}

As shown in Figure 5, after $S$. aureus and E. coli were co-cultured for 12 and $24 \mathrm{~h}$, the antibacterial activity was determined. The groups were in the following order of antibacterial activity: $\mathrm{D}>\mathrm{C}>\mathrm{B}>\mathrm{A}>$ control. There was no significance $(P>0.05)$ between group A and group $\mathrm{B}$, but the differences among other groups were statistically significant $(P<0.05)$.

\section{Antipollution experiment in vitro}

As shown in Figure 6, the antipollution activity of groups was in the order $\mathrm{D}>\mathrm{B}>\mathrm{C}>\mathrm{A}$, and the difference was statistically significant $(P<0.05)$.
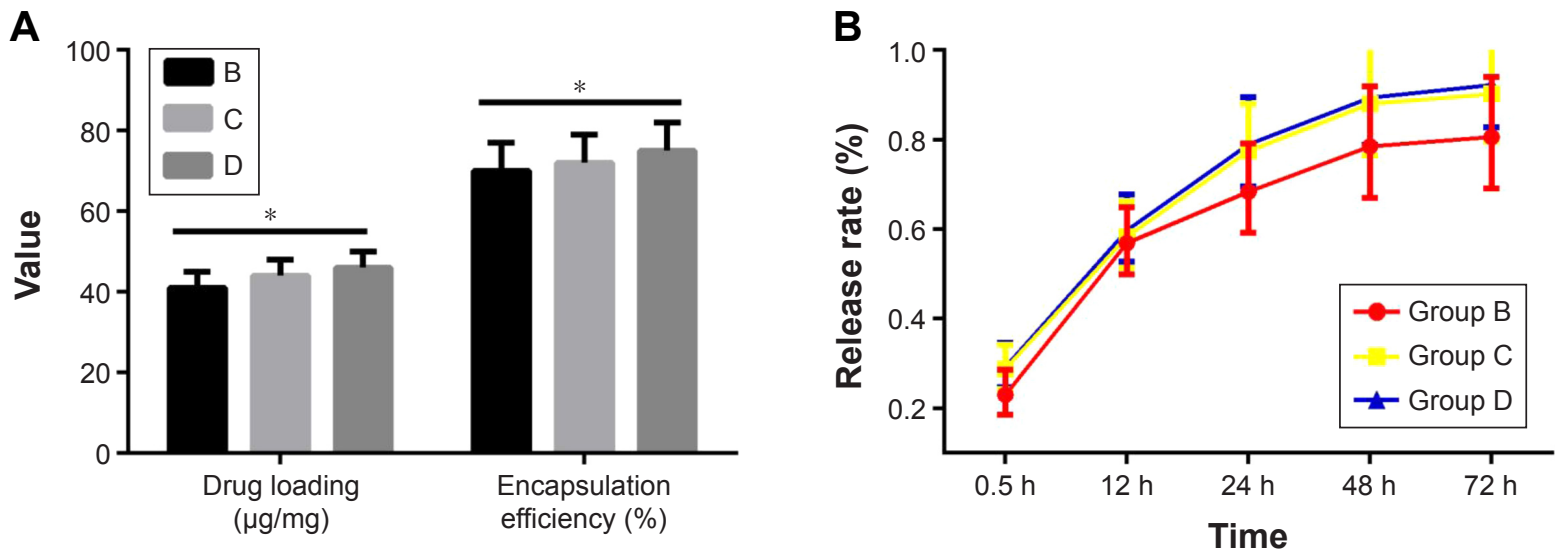

Figure 4 (A) The drug loading and entrapment efficiency for the materials from groups B-D. (B) The release rate of groups B-D, respectively.

Note: Group B (chitin + amphiphilic ion), group C (chitin + quaternary ammonium salt), and group D (chitin + amphiphilic ion + quaternary ammonium salt). *Represents $P<0.05$. 


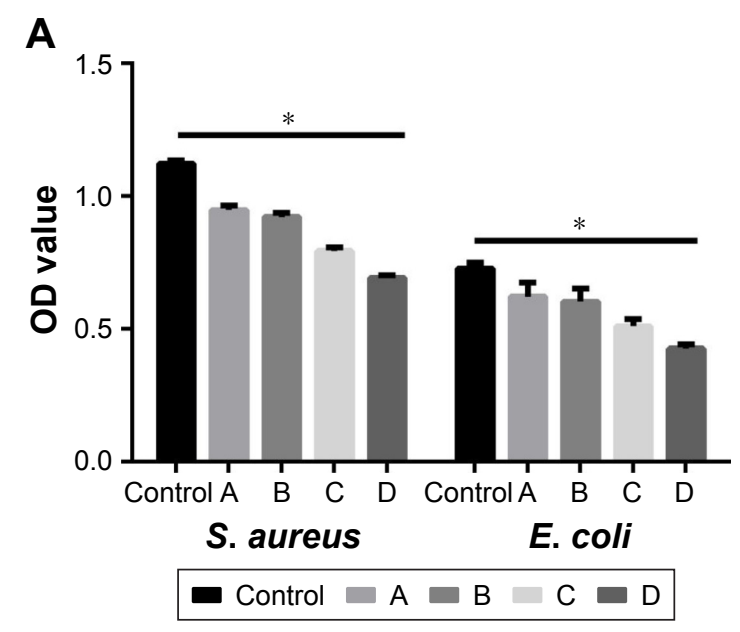

B

S. aureus

\begin{tabular}{llllll}
\hline & Control & A & B & C & D \\
\hline $12 \mathrm{~h}$ & $0.717 \pm 0.105$ & $0.683 \pm 0.102$ & $0.562 \pm 0.098$ & $0.535 \pm 0.074$ & $0.492 \pm 0.069$ \\
$24 \mathrm{~h}$ & $1.122 \pm 0.177$ & $0.949 \pm 0.173$ & $0.921 \pm 0.165$ & $0.795 \pm 0.121$ & $0.692 \pm 0.108$ \\
\hline
\end{tabular}

E. coli

\begin{tabular}{llllll}
\hline & Control & A & B & C & D \\
\hline $12 \mathrm{~h}$ & $0.503 \pm 0.095$ & $0.472 \pm 0.086$ & $0.410 \pm 0.073$ & $0.327 \pm 0.069$ & $0.301 \pm 0.061$ \\
$24 \mathrm{~h}$ & $0.739 \pm 0.099$ & $0.622 \pm 0.104$ & $0.604 \pm 0.101$ & $0.511 \pm 0.095$ & $0.427 \pm 0.090$ \\
\hline
\end{tabular}

Figure 5 Assay of antibacterial activity.

Notes: (A) The OD value of control group and groups A, B, C, and D in $24 \mathrm{~h}$. (B) Different strains of each group at different time points of specific antimicrobial OD. *Represents $P<0.05$. Group $A$ (chitin), group $B$ (chitin + amphiphilic ion), group $C$ (chitin + quaternary ammonium salt), and group $D$ (chitin + amphiphilic ion + quaternary ammonium salt). Abbreviations: S. aureus, Staphylococcus aureus; E. coli, Escherichia coli.

\section{Test of cytotoxicity}

Based on the data in Figure 7, samples from the four groups showed virtually no proliferation inhibition of cells during 1-5 days $(P>0.05)$, and only group D showed slight inhibition on Day $7(P<0.05)$.

\section{Effect on infectious wound healing}

As shown in Figure 8, the wound healing rates of the CCD, control, A, B, C, and D groups, respectively, were $31.1 \%$, $17.9 \%, 23.8 \%, 29.3 \%, 35.6 \%$, and $41.5 \%$ after 3 days of injury, showing the order $\mathrm{D}>\mathrm{C}>\mathrm{CCD} \approx \mathrm{B}>\mathrm{A}>$ control $(P<0.05)$. These rates increased to $61.1 \%, 34.6 \%, 44.7 \%$, $59.8 \%, 64.2 \%$, and $76.4 \%$, respectively, after 7 days of injury. The observed order was $\mathrm{D}>\mathrm{C}>\mathrm{CCD} \approx \mathrm{B}>\mathrm{A}>$ control, with no obvious difference between group $\mathrm{B}$ and group $\mathrm{C}$ $(P>0.05)$.

\section{New epithelial length}

As shown in Figure 9, there were no differences in length among groups after 3 days of injury $(P>0.05)$, and the wound epithelial lengths of $\mathrm{CCD}$, control, $\mathrm{A}, \mathrm{B}, \mathrm{C}$, and $\mathrm{D}$ groups after 7 days injury were, respectively, 847.0, 635.3, 717.2,
843.8, 865.7, and $986 \mu \mathrm{m}$, showing a decreasing order of $\mathrm{D}>\mathrm{C}>\mathrm{CCD} \approx \mathrm{B}>\mathrm{A}>$ control $(P<0.05)$.

\section{Cell proliferation and angiogenesis}

As shown in Figure 10, PCNA and CD31 expression were determined and the results indicated that cell proliferation and angiogenesis were enhanced when skin defects were covered with the $\mathrm{D}$ group material $(P<0.05)$, which significantly accelerated wound healing.

\section{Discussion}

For patients with severe skin lesions, it is urgent to quickly and effectively close the wound to prevent bacterial invasion and prevent the loss of body fluids, energy, water, and electrolytes. Wound dressings can rebuild the skin barrier, accelerate wound healing, and protect and prepare the skin for later operation. ${ }^{14}$ Ideal wound dressings should have good mechanical properties, adequate water vapor permeability, and excellent biocompatibility. More importantly, the infection and inflammatory disorder may slow or inhibit wound healing; so, an ideal wound dressing should also provide a sterile and suitable microenvironment for healing. ${ }^{15,16}$ 


\section{A}
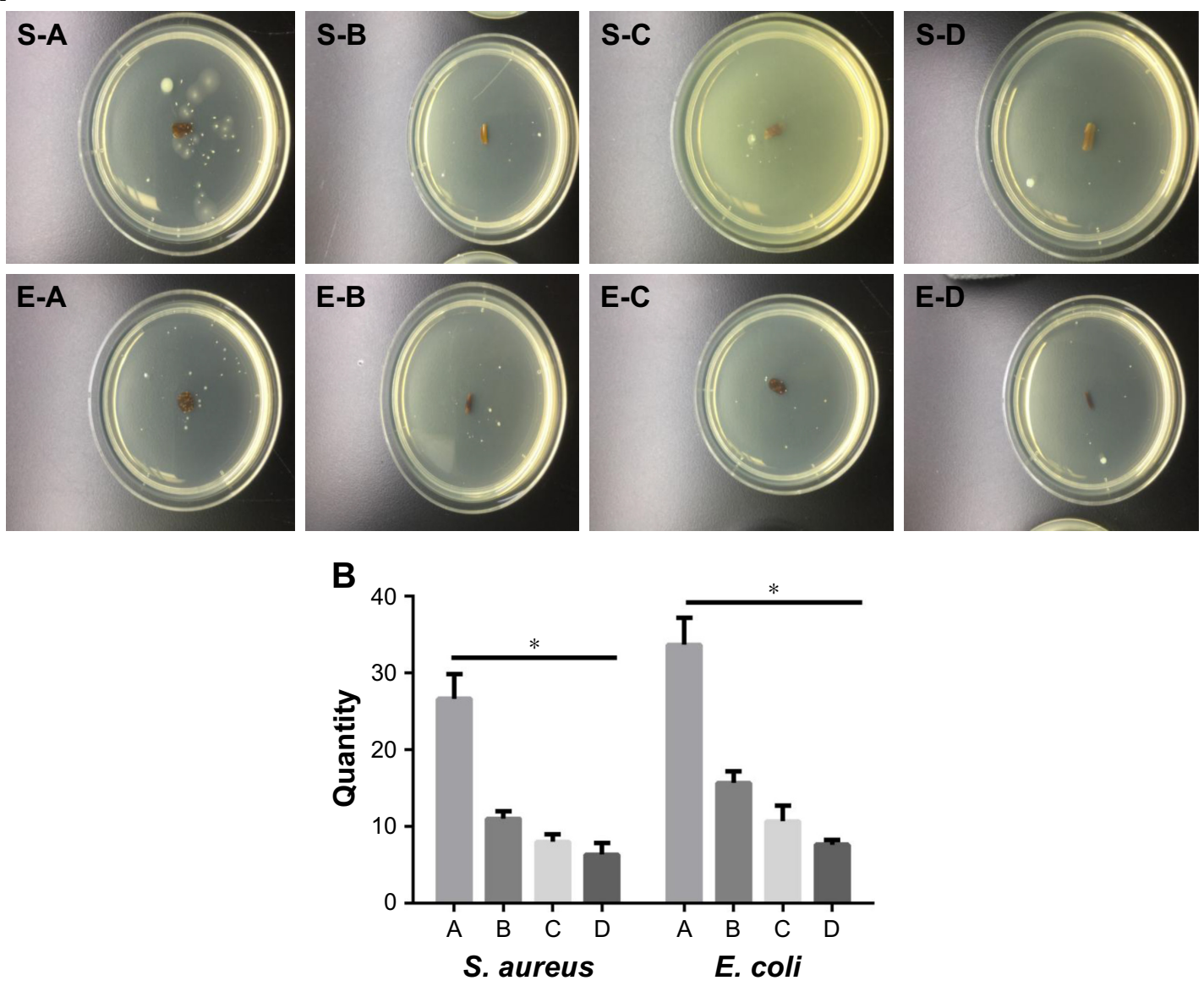

Figure 6 Antipollution experiment in vitro.

Notes: (A) The small circle in the center of the culture dish is the material and the surrounding white spot is the adherent cells colony. (B) The number of adherent cells in the different groups. *Represents $P<0.05$. Group $A$ (chitin), group $B$ (chitin + amphiphilic ion), group $C$ (chitin + quaternary ammonium salt), and group $D$ (chitin + amphiphilic ion + quaternary ammonium salt). "S" represents $S$. aureus; "E" represents $E$. coil; " $A$ " "B" "C" " $D$ " represents groups $A, B, C$, and D. Abbreviations: S. aureus, Staphylococcus aureus; E. coli, Escherichia coli.

\section{A Control}

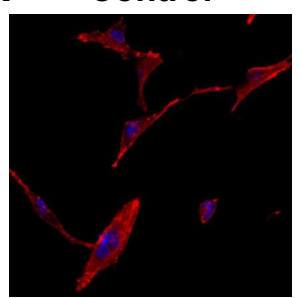

A

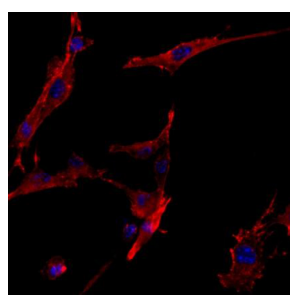

B
B
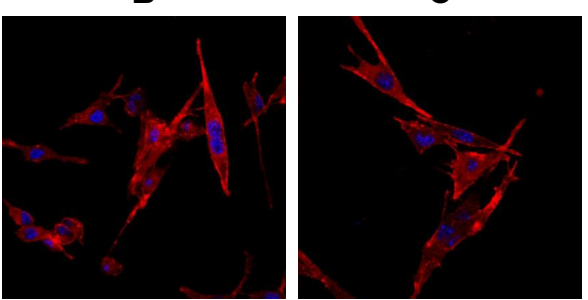

D
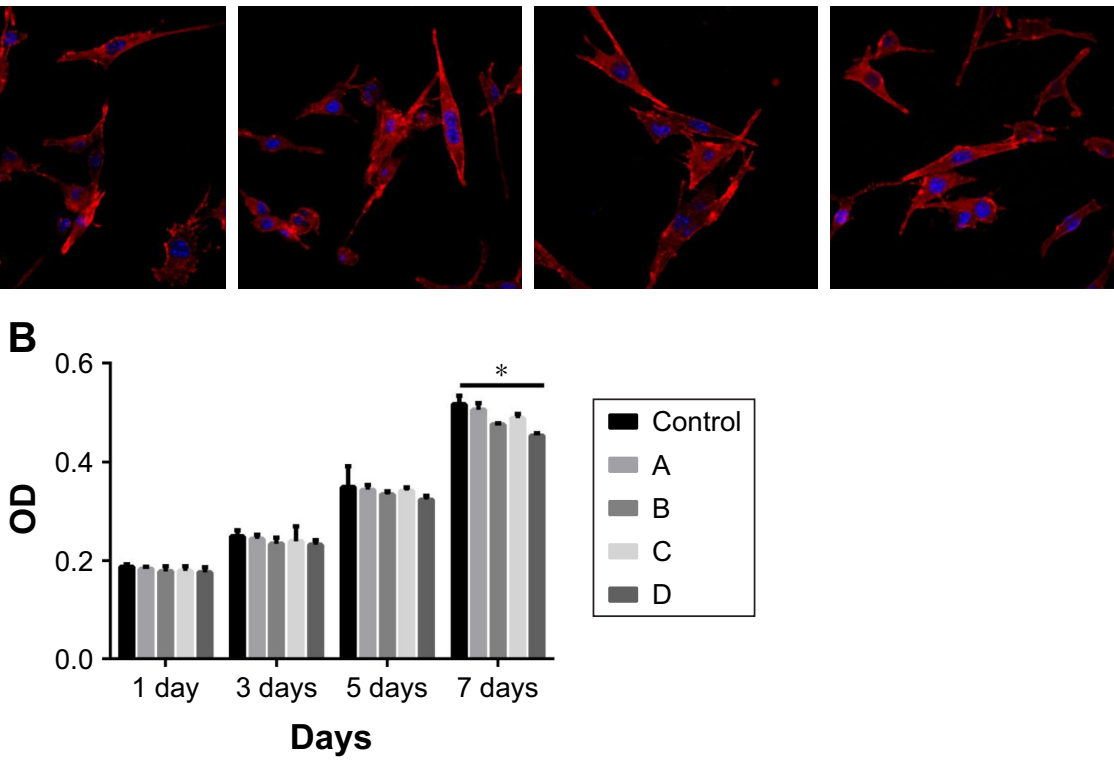

Figure 7 Test of cytotoxicity.

Notes: (A) Cytostaining image. Red areas indicate cytoplasm and the blue areas show the nucleus. (B) The statistics of cell proliferation. *Represents $P<0.05$. Group A (chitin), group B (chitin + amphiphilic ion), group C (chitin + quaternary ammonium salt), and group $D$ (chitin + amphiphilic ion + quaternary ammonium salt). 
A

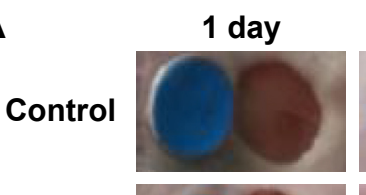

A

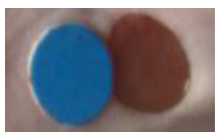

B

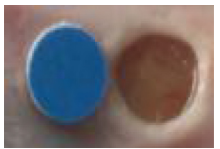

C

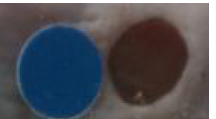

D

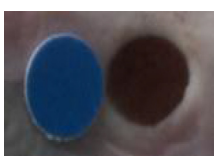

\section{CCD}

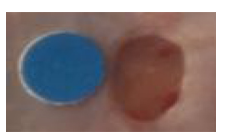

B

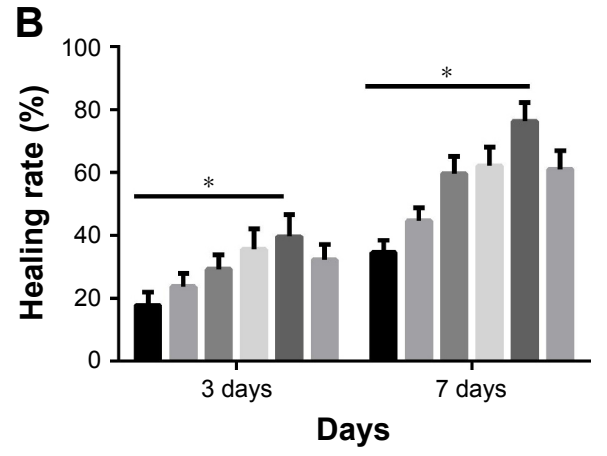

3 days
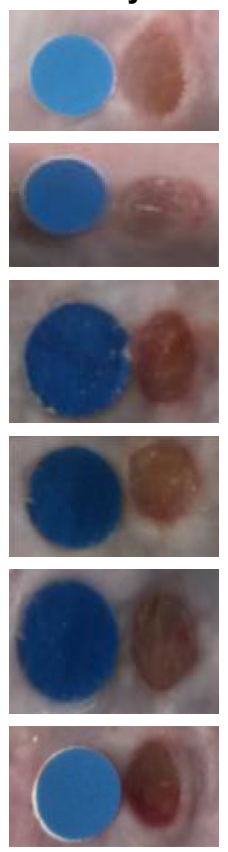

5 days
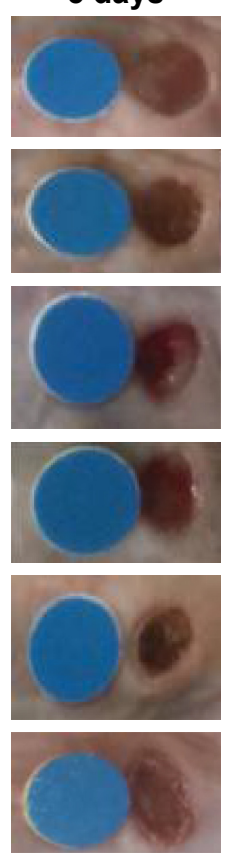

C

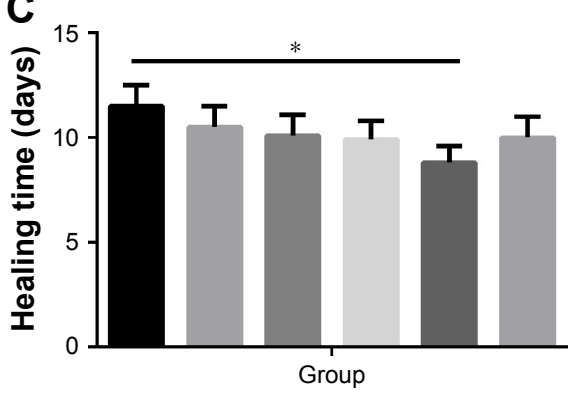

7 days
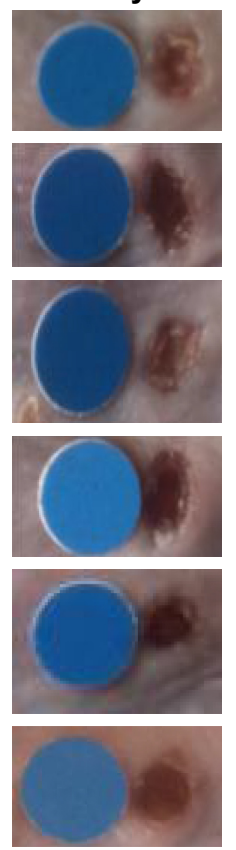

- Control $\square \mathrm{A} \square \mathrm{B} \square \mathrm{C} \square \mathrm{D} \square \mathrm{CCD}$

Figure 8 Effect on infectious wound healing.

Notes: (A) Wound healing map, the small round is the standard reference. (B) The wound healing statistics on days 3 and 7. (C) The time that the wound required for complete healing. *Represents $P<0.05$. Group A (chitin), group B (chitin + amphiphilic ion), group $C$ (chitin + quaternary ammonium salt), and group $D$ (chitin + amphiphilic ion + quaternary ammonium salt).

Abbreviation: CCD, commercial chitin dressing.

Natural materials such as chitin, chitosan, dextran, cellulose, alginate, and silk protein are considered suitable to make wound dressings because of their easy preparation and good biocompatibility. Therefore, natural material loaded with a variety of antibacterial agents, growth factors, or other chemicals to promote the healing of infectious wounds has become a hot spot in the field of wound repair. ${ }^{17,18}$

In recent years, the use of chitin and chitin quaternary ammonium salts in medicine has attracted much attention, and they have been used to develop absorbable surgical sutures, medical dressings, artificial skin, cell-bound drugs, anticoagulants, and artificial kidney membranes. Chitosan is characterized by three functional groups, an amino, acetamido, and hydroxyl groups. Cationic character of amino group (after its potentization) gives good opportunities for it to react with other compounds, and the key properties of chitosan include its bactericidal, fungicidal, and immune-enhancing properties. Also, chitosan is water soluble in acidic media due to the protonation of amino group on the second carbon of glucosamine. ${ }^{19}$ The quaternary ammonium salts of chitin are soluble in water over a wide range of $\mathrm{pH}$ values, an improvement over chitin that can only be dissolved in acidic conditions. Therefore, the application of chitin quaternary ammonium salt in medicine has become more extensive than that of chitosan. ${ }^{3,20}$ In addition, studies have reported the preparation of carboxymethyl chitosan octadecyl quaternary ammonium salt liposomes containing fat-soluble and water-soluble drugs by microemulsion method, which 

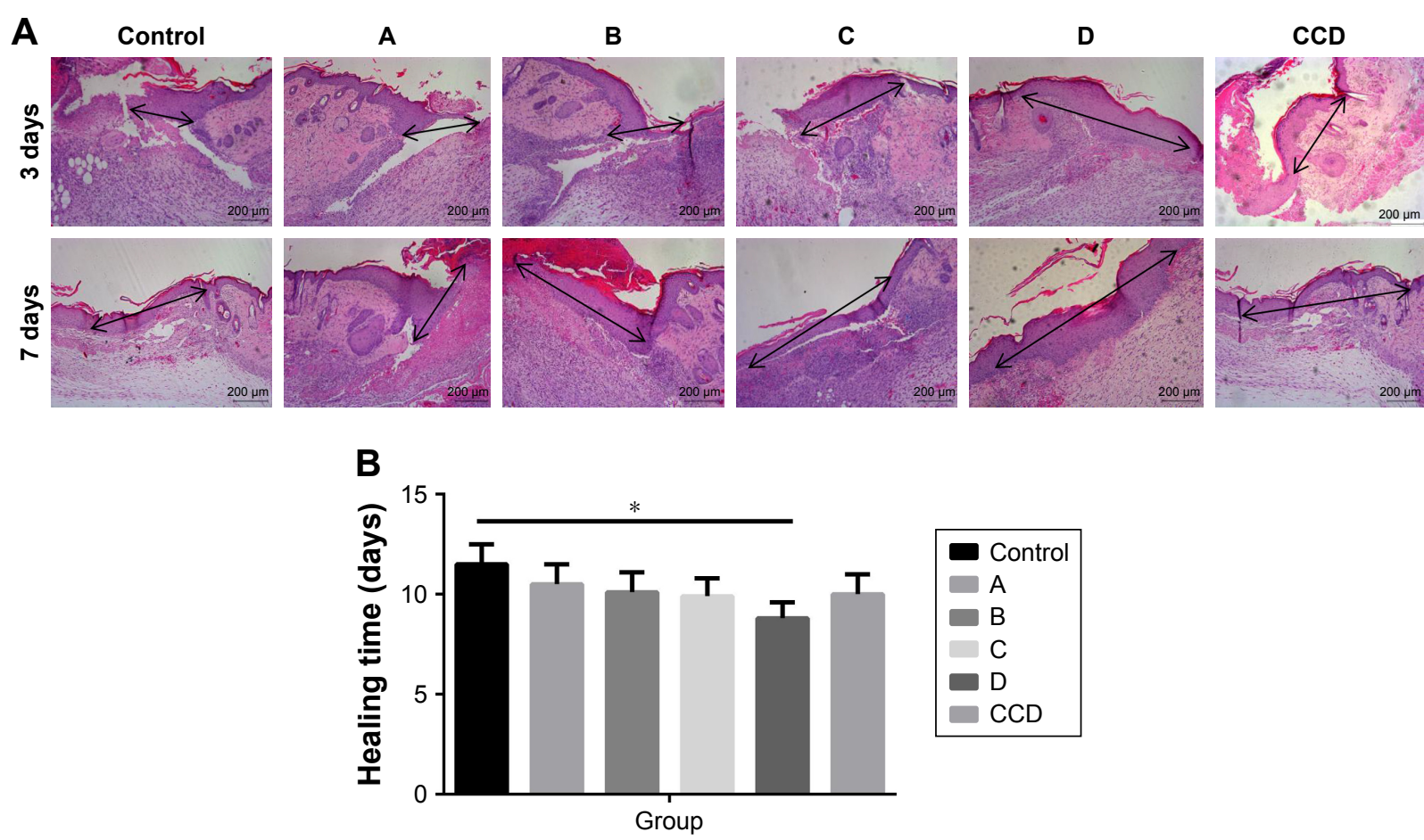

Figure $9 \mathrm{HE}$ staining of new epithelial length.

Notes: (A) The length of the arrow represents the length of the new epithelium. (B) The statistics of length of the new epithelium. *Represents $P<0.05$. Group A (chitin), group B (chitin + amphiphilic ion), group C (chitin + quaternary ammonium salt), and group D (chitin + amphiphilic ion + quaternary ammonium salt).

Abbreviations: $\mathrm{CCD}$, commercial chitin dressing; HE, hematoxylin-eosin staining.

allow slow drug release. ${ }^{21}$ As shown in Figure 2, compared to the conventional chitin structure in group $\mathrm{A}$, a brush-like structure layer was visible under D1. The rules and texture structure changed under D2 and precipitated and bedding amphiphilic ion/quaternary ammonium salt layers were visible under D3. This is because the structure of chitin itself was changed by the composite reaction, so that the amphiphilic ion/quaternary ammonium salt became effectively attached to it, consistent with the structure observed by Gopi et $\mathrm{al}^{22}$ and Sahraee et al using SEM. ${ }^{23}$ Some studies suggest that the chitin fiber is intertwined with the fiber and presents a typical three-dimensional network structure. ${ }^{20}$ There is a certain gap between the filaments, which indicates that the proteins and calcium carbonate in the shell have been removed. ${ }^{22}$ The average contact angle $(\theta)$ of $\mathrm{A}$ was $69.86^{\circ} \pm 6.85^{\circ}$, B was $72.62^{\circ} \pm 7.05^{\circ}, \mathrm{C}$ was $74.38^{\circ} \pm 7.29^{\circ}$,

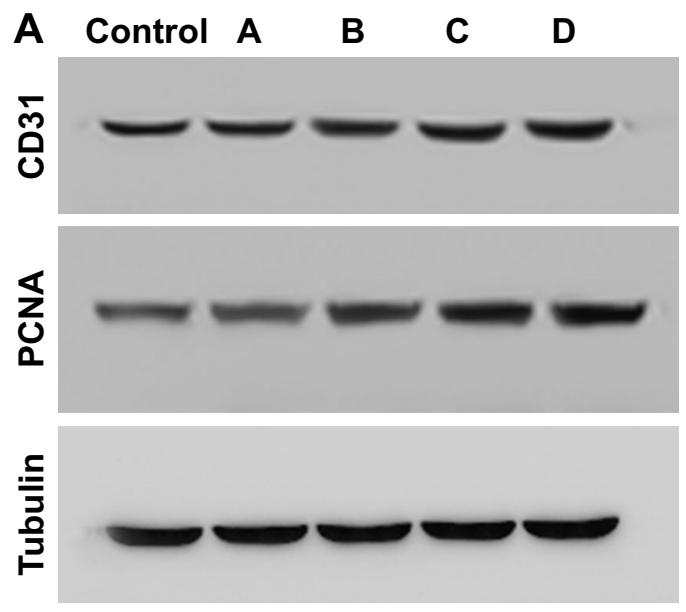

\section{B}

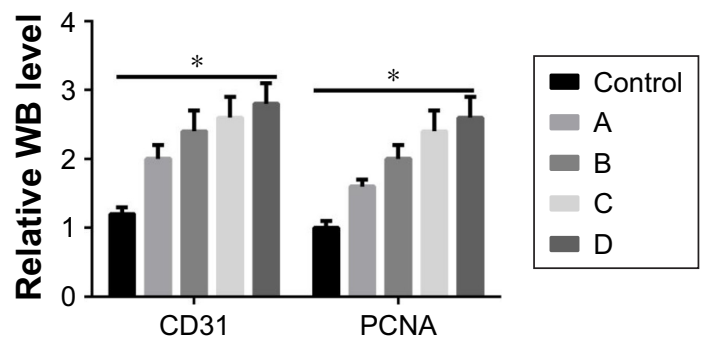

Figure 10 Western blot to detect PCNA and CD3I expression.

Notes: (A) The protein levels of PCNA and CD3I in the full-thickness wound tissues, as determined by Western blot. (B) The OD values of the PCNA and CD3I bands in each group. *Represents $P<0.05$. Group $A$ (chitin), group $B$ (chitin + amphiphilic ion), group $C$ (chitin + quaternary ammonium salt), and group $D$ (chitin + amphiphilic ion + quaternary ammonium salt).

Abbreviations: PCNA, proliferating cell nuclear antigen; WB, Western blot. 
and $\mathrm{D}$ was $78.03^{\circ} \pm 7.50^{\circ}$. Comparison of the four groups showed no significant difference $(P>0.05)$. All materials remained hydrophilic, indicating that the preparation did not change the characteristics of the material itself. This may be related to the internal hydrophobicity of chitin and the basic structure of the external hydrophilic layer, which plays an important role in chitin lysozyme's antibacterial function..$^{20,21}$ As shown in Figure 4, the drug loading rate in groups B, C, D was 40-50 ( $\mu \mathrm{g}: \mathrm{mg})$, and the entrapment efficiency was $70 \%-75 \%$. There was no difference between groups $(P>0.05)$, indicating that this method was effective for lysozyme embedding. The release rate of the materials tended to be stable and maximum at $72 \mathrm{~h}$, and the cumulative release percentages were $87.3 \%, 88.7 \%$, and $90.2 \%$ after $72 \mathrm{~h}$ in groups B, C, and D, respectively. Some studies have shown that when the hydrophobicity of drug loading microspheres increases, the stronger the intermolecular force between chitin and hydrophobic drugs, the more hydrophobic drugs can be coated. ${ }^{16}$ For example, when the degree of alkylation is $67 \%$, the drug loading amount is $51 \%$ and the encapsulation efficiency is also $83 \%{ }^{3}$ Studies have also suggested that with the increase of the ratio of drug and carrier, the drug loading increases; the reason is when the quality of microspheres under the same condition, the adsorption to the drug carrier within more than a certain adsorption time of microspheres after adding a saturated load of drugs, the encapsulation rate becomes smaller. ${ }^{22}$ As shown in Figure 5, similar to what was observed for the release of drugs, the materials released faster in the first $24 \mathrm{~h} .{ }^{3,21}$ When B, C, or D group was cultured in PBS buffer solution, the chitin-amphipathic anion/quaternary ammonium salt was easily released to PBS through the chitin surface structure, resulting in an increase in release. ${ }^{4,7,8}$ After $72 \mathrm{~h}$, the amount released from chitin remained almost unchanged, indicating that the release had stabilized and reached its maximum, nearly $85 \%-90 \%$.

$S$. aureus and E. coli were co-cultured together for 12 and $24 \mathrm{~h}$, and the antibacterial activity of the groups was in the order $\mathrm{D}>\mathrm{C}>\mathrm{B}>\mathrm{A}>$ control. Only the difference between group A and group B was not significant $(P>0.05)$, and the differences between the remaining groups were statistically significant $(P<0.05)$. Thus, the antibacterial activity of the chitin quaternary ammonium salt, group $\mathrm{D}$, was significantly stronger, and the amphiphilic ions played an important synergistic role. This study suggests that the chitin quaternary ammonium salt has strong antibacterial activity and a wide antibacterial spectrum, making it difficult to produce drug-resistant strains. It also offers unique advantages in the prevention and treatment of wound infection..$^{9-11}$ Some in vitro experiments showed that chitin/chitosan quaternary ammonium salt could effectively inhibit and kill bacteria and fungi as a nanocomposite, typically with higher antibacterial activity. ${ }^{24,25}$ Some mechanism studies suggest that, as the concentration of CH-g-AT2 increases $(5,10$, and $15 \mathrm{mg})$, the antibacterial activity increases. However, the reduction rate was $<100 \%$, which is due to the blocking/masking of the amino groups in chitosan chain by $N$-(anthracen-9-yl)-4,6dichloro-[1,3,5]-triazin-2-amine, in addition to the acetylation of amino groups of chitosan; both lead to decrease in the antibacterial activity of chitosan derivatives. ${ }^{26}$ In addition, although in vitro experiments showed that chitin quaternary ammonium salt showed a stronger antibacterial activity than chitin, its antibacterial activity was also affected by the degree of quaternization, alkyl chain length, the $\mathrm{pH}$ of the solution, and many other factors. ${ }^{27,28}$ Therefore, the use of a specific chitin quaternary ammonium salt for practical application of antibacterial activity requires further study. The antipollution activity of the groups was in the decreasing order $\mathrm{D}>\mathrm{B}>\mathrm{C}>\mathrm{A}$, and the difference between the groups was statistically significant $(P<0.05)$. The amphiphilic ions have both hydrophilicity and lipophilicity and a good antipollution effect. The mechanism may be to reduce the interaction between proteins and bacteria, or microorganisms and surfaces, thereby reducing the adhesion strength. ${ }^{29}$ It has also been suggested that amphiphilic ions can reduce the surface energy by changing the surface morphology, charge, mobility, and mechanical properties of the surface groups. Some studies have also suggested that two ions could also reduce the surface energy by changing the morphology, charge, mobility, and mechanical properties of the surface groups. ${ }^{30}$ Therefore, it is of growing interest to study the development of amphiphilic surfaces with high resistance to biologic adhesion by combining polymers with hydrophilic antibacterial properties and materials with hydrophobic polymers or low surface energy. ${ }^{12,13}$

Cytotoxicity was observed only on the seventh day, and group D exhibited slightly increased suppression of cell proliferation $(P<0.05)$. This may be related to some characteristics of chitosan, chitosan quaternary ammonium salts, or amphiphilic ions. For example, they are all safe and nontoxic, enabling use in the food industry as a food preservative and additive. ${ }^{31,32}$ It is also considered that natural materials have low toxicity and are especially suitable for modified wound dressings. Because of the destruction of the defense barrier of burn patients both internally and on the body surface, patients' immune ability typically decreases significantly, and extensive tissue necrosis and the invasion of bacteria can lead to wound infection. ${ }^{33}$ Wound infection is a major cause of complications and death in burn patients, 
and about $52 \%-70 \%$ of burn patients die due to wound infection. ${ }^{34}$ In this study, a mature mouse wound infection model was used. Mixed liquid of common gram-positive bacteria (S. aureus) and gram-negative bacteria (E. coli) was dropped into the wound infection at bacterial concentrations of $10^{8} / \mathrm{mL} .^{35-37}$ A CCD of Beschitin W has been used since the 1990s. It can inserted into or cover the wound to alleviate wound deformity and promote wound healing rate. The wound healing rates increased to $61.1 \%, 34.6 \%, 44.7 \%$, $59.8 \%, 64.2 \%$, and $76.4 \%$ after 7 days of injury. The observed order was $\mathrm{D}>\mathrm{C}>\mathrm{CCD} \approx \mathrm{B}>\mathrm{A}>$ control, with no obvious difference between group $\mathrm{B}$ and group $\mathrm{C}(P>0.05)$. This suggested that the quaternary ammonium salts played a major antimicrobial role on the wound surface during the initial period (0-3 days) to mainly control the infection. After we infected the mice with the full-thickness skin defect wound model, CCD had no significant effect compared with group B and group C. If the two materials acted synergistically, as in group D, the bacterial growth could be maximally inhibited. In a study, Vinachitin was prepared by noncrystallization of crab chitin to treat $>300$ severe burns, trauma, and ulcer; the result showed that the product had a good effect on wound healing. ${ }^{35}$ Studies have also found that chitin can directly stimulate fibroblasts to secrete interleukin- 8 to promote the proliferation of vascular endothelial cells in wound, thereby increasing the blood supply and promoting granulation tissue growth. ${ }^{37}$ The process of wound healing requires wound contraction and wound epithelialization. For compact skin species (eg, humans), the wound healing mainly depends on the re-epithelialization of the wound surface. ${ }^{38}$ There was no observed difference in the length of neonatal epithelium in each group, 3 days after injury. This was mainly because the edge of the wound remained in the preparation period of cell proliferation and migration, and the neonatal epithelium was not yet obvious. ${ }^{39}$ The wound epithelial lengths of CCD, control, A, B, C, and D groups after 7 days of injury were, respectively, 847.0, 635.3, 717.2, 843.8, 865.7, and $986 \mu \mathrm{m}$, showing the decreasing order of $\mathrm{D}>\mathrm{C}>\mathrm{CCD} \approx \mathrm{B}>\mathrm{A}>$ control $(P<0.05)$. The chitin compound quaternary ammonium salt/ amphiphilic ion could accelerate the healing of the wound by controlling infection and antibacterial adhesion during the late period of injury (7 days after injury). However, other mechanisms to promote re-epithelialization may also contribute. ${ }^{40,41}$ PCNA expression and the repair of the wound are accompanied by the regeneration of blood vessels to provide a large number of nutrients. CD31 can specifically mark the vascular endothelial cells, and the blood vessel density can be used as an indicator of angiogenesis. PCNA is present in the nucleus, which is the helper protein of
DNA polymerase. It is necessary for DNA replication in $\mathrm{S}$ phase and plays an important role in cell proliferation. CD31 expression was determined, and the results indicated that cell proliferation and angiogenesis were enhanced when skin defects were covered with the D group material $(P<0.05)$, which significantly accelerated wound healing.

\section{Conclusion}

The study has some limitations. For example, the appearance of the dressing preparation needs to be improved to look more like dressings made from other conventional materials. In future studies, we will further design and study modified materials.

In summary, chitin-amphiphilic ion/quaternary ammonium salt dressing was successfully prepared. The antibacterial and antipollution effects of the prepared material (group D; chitin + amphiphilic ion + quaternary ammonium salt) were both very good, acting to promote wound healing. Overall, this study reveals a promising new material for a natural dressing for wound application.

\section{Author contributions}

All authors contributed to the study design; DZ, MX, and GL designed experiments and conducted research; TY and RY analyzed data and prepared tables and figures; DZ wrote the manuscript; and all authors contributed to the interpretation of results and the revision of the manuscript.

\section{Disclosure}

The authors report no conflicts of interest in this work.

\section{References}

1. Azuma K, Izumi R, Osaki T, et al. Chitin, chitosan, and its derivatives for wound healing: old and new materials. J Funct Biomater. 2015;6(1): 104-142.

2. Izumi R, Komada S, Ochi K, et al. Favorable effects of superficially deacetylated chitin nanofibrils on the wound healing process. Carbohydr Polym. 2015;123:461-467.

3. Tabuchi R, Azuma K, Izumi R, et al. Biomaterials based on freeze dried surface-deacetylated chitin nanofibers reinforced with sulfobutyl ether beta-cyclodextrin gel in wound dressing applications. Int J Pharm. 2016;511(1):1080-1087.

4. Shao K, Han B, Gao J, et al. Fabrication and feasibility study of an absorbable diacetyl chitin surgical suture for wound healing. J Biomed Mater Res B Appl Biomater. 2016;104(1):116-125.

5. Abdelmohsen AM, Jancar J, Massoud D, et al. Novel chitin/chitosanglucan wound dressing: isolation, characterization, antibacterial activity and wound healing properties. Int J Pharm. 2016;510(1):86-99.

6. Abdel-Mohsen AM, Aly AS, Hrdina R, El-Aref AT. A novel method for the preparation of silver/chitosan-O-methoxy polyethylene glycol core shell nanoparticles. J Polym and Environ. 2012;20(2): 459-468.

7. Watthanaphanit A, Rujiravanit R. Sericin-binded-deprotenized natural rubber film containing chitin whiskers as elasto-gel dressing. Int J Biol Macromol. 2017;101:417-426. 
8. Jin Y, Pei Y, Hu W, et al. A promising application of chitosan quaterdrinking water. Sci Total Environ. 2017;583:496-504.

9. Song R, Zhong Z, Lin L. Evaluation of chitosan quaternary ammonium salt-modified resin denture base material. Int J Biol Macromol. 2016;85 $102-110$.

10. Singh R, Shitiz K, Singh A. Chitin and chitosan: biopolymers for wound management. Int Wound J. 2017;14(6):1276-1289.

11. Liu P, Meng W, Wang S, et al. Quaternary ammonium salt of chitosan: 10(1):473-478.

12. Takechi-Haraya Y, Tanaka K, Tsuji K, et al. Molecular complex composed of beta-cyclodextrin-grafted chitosan and $\mathrm{pH}$-sensitive amphipathic peptide for enhancing cellular cholesterol efflux under acidic pH. Bioconjug Chem. 2015;26(3):572-581.

13. Guo F, Zhang M, Gao Y, et al. Modified nanoparticles with cellpenetrating peptide and amphipathic chitosan derivative for enhanced oral colon absorption of insulin: preparation and evaluation. Drug Deliv 2015;23(6):2003.

14. Guo S, Dipietro LA. Factors affecting wound healing. Otolaryngol Clin North Am. 1984;17(2):243.

15. Morsy R, Hosny M, Reicha F, Elnimr T. Development and characterization of multifunctional electrospun ferric oxide-gelatin-glycerol nanofibrous mat for wound dressing applications. Fibers Polym 2016;17(12):2014-2019.

16. Chan LW, Kim CH, Wang X, Pun SH, White NJ, Kim TH. PolySTATmodified chitosan gauzes for improved hemostasis in external hemorrhage. Acta Biomater. 2016;31:178-185.

17. Dreifke MB, Jayasuriya AA, Jayasuriya AC. Current wound healing procedures and potential care. Mater Sci Eng C Mater Biol Appl. 2015; 48:651-662.

18. Wang Y, Xu R, Luo G, et al. Biomimetic fibroblast-loaded artificial dermis with "sandwich" structure and designed gradient pore sizes promotes wound healing by favoring granulation tissue formation and wound re-epithelialization. Acta Biomater. 2016;30:246-257.

19. Abdel-Rahman RM, Abdel-Mohsen AM, Hrdina R, et al. Wound dressing based on chitosan/hyaluronan/nonwoven fabrics: preparation, characterization and medical applications. Int J Biol Macromol. 2016;89:725-736.

20. Izumi R, Komada S, Ochi K, et al. Novel chitin/chitosan-glucan wound dressing: isolation, characterization, antibacterial activity and wound healing properties. Carbohydr Polym. 2015;123:461-467.

21. Ljang XF, Hu JY, Chen FH, Li ZH, Chang J. Characterization of and hydrophilic drugs prepared by a microemulsion method. Acta Phys Chim Sin. 2012;28(4):897-902.

22. Gopi S, Balakrishnan P, Pius A, Thomas S. Chitin nanowhisker (ChNW)-functionalized electrospun PVDF membrane for enhanced removal of Indigo carmine. Carbohydr Polym. 2017;165:115-122.

23. Sahraee S, Milani JM, Ghanbarzadeh B, Hamishehkar H. Physicochemical and antifungal properties of bio-nanocomposite film based on gelatin-chitin nanoparticles. Int J Biol Macromol. 2017;97: 373-381.

24. Wei L, Li Q, Tan W, Dong F, Luan F, Guo Z. Synthesis, characterization, and the antioxidant activity of double quaternized chitosan derivatives. Molecules. 2017;22(3):501. nary ammonium salt to removal of Microcystis aeruginosa cells from preparation and antimicrobial property for paper. Open Med. 2015; chitosan polymeric ethosomes capable of encapsulating hydrophobic

25. Tang R, Zhang Y, Zhang Y, Yu Z. Synthesis and characterization of chitosan based dye containing quaternary ammonium group. Carbohydrate Polym. 2016;139:191-196.

26. Přichystalová H, Almonasy N, Abdel-Mohsen AM, et al. Synthesis, characterization and antibacterial activity of new fluorescent chitosan derivatives. Int J Biol Macromol. 2014;65(5):234-240.

27. Wang CH, Liu WS, Sun JF, et al. Non-toxic O-quaternized chitosan materials with better water solubility and antimicrobial function. Int $J$ Biol Macromol. 2014;84:418-427.

28. Wang Z, Yan Y, Yu X, Li W, Li B, Qin C. Protective effects of chitosan and its water-soluble derivatives against lead-induced oxidative stress in mice. Int J Biol Macromol. 2015;83:442-449.

29. Gao J, Yan A, Ni H, Wang L, Yang Y, Wang X. Protein-resistance performance enhanced by formation of highly-ordered perfluorinated alkyls on fluorinated polymer surfaces. J Colloid Interface Sci. 2013; 393(1):361-368.

30. Krishnan S, Weinman C, Ober C. Advances in polymers for antibiofouling surfaces. Mater Chem. 2008;18(29):3405-3413.

31. Zhang W, Wang Y, Sui X, Sun Y, Chen D. Effects of chitin and sepia ink hybrid sponge on the healing of burning wound rats and its impact on macrophages in vitro. Acta Cir Bras. 2016;31:119-125.

32. Li K, Li P, Cai J, Xiao S, Yang H, Li A. Efficient adsorption of both methyl orange and chromium from their aqueous mixtures using a quaternary ammonium salt modified chitosan magnetic composite adsorbent. Chemosphere. 2016;154:310-318.

33. Fournier A, Eggimann P, Pagani JL, et al. Impact of the introduction of real-time therapeutic drug monitoring on empirical doses of carbapenems in critically ill burn patients. Burns. 2015;41(5):956-968.

34. Ito K, Saito A, Fujie T, et al. Sustainable antimicrobial effect of silver sulfadiazine-loaded nanosheets on infection in a mouse model of partialthickness burn injury. Acta Biomater. 2015;24:87-95.

35. Costley D, Nesbitt H, Ternan N, et al. Sonodynamic inactivation of Gram-positive and Gram-negative bacteria using a Rose Bengalantimicrobial peptide conjugate. Int J Antimicrob Agents. 2016;49(1): 31-36.

36. Sarhan WA, Azzazy HM, El-Sherbiny IM. Honey/chitosan nanofiber wound dressing enriched with Allium sativum and Cleome droserifolia: enhanced antimicrobial and wound healing activity. ACS Appl Mater Interfaces. 2016;8(10):6379-6390.

37. Chadha P, Katare OP, Chhibber S. In vivo efficacy of single phage versus phage cocktail in resolving burn wound infection in BALB/c mice. Microb Pathog. 2016;99:68-77.

38. Jangpromma N, Preecharram S, Srilert T, et al. In vitro and in vivo wound healing properties of plasma and serum from crocodylus siamensis blood. J Microbiol Biotechnol. 2016;26(6):1140-1147.

39. Liang D, Lu Z, Yang H, Gao J, Chen R. Novel asymmetric wettable AgNPs/chitosan wound dressing: in vitro and in vivo evaluation. $A C S$ Appl Mater Interfaces. 2016;8(6):3958-3968.

40. Majchrzak K, Kaspera W, Szymas J, Bobek-Billewicz B, Hebda A, Majchrzak H. Markers of angiogenesis (CD31, CD34, rCBV) and their prognostic value in low-grade gliomas. Neurol Neurochir Pol. 2013;47(4):325-331.

41. Liu L, Qi T, Liu S, et al. ZEB1 Upregulates VEGF expression and stimulates angiogenesis in breast cancer. PLoS One. 2016;11(2):e0148774

International Journal of Nanomedicine

\section{Publish your work in this journal}

The International Journal of Nanomedicine is an international, peerreviewed journal focusing on the application of nanotechnology in diagnostics, therapeutics, and drug delivery systems throughout the biomedical field. This journal is indexed on PubMed Central, MedLine, CAS, SciSearch $®$, Current Contents $\AA /$ Clinical Medicine,

\section{Dovepress}

Journal Citation Reports/Science Edition, EMBase, Scopus and the Elsevier Bibliographic databases. The manuscript management system is completely online and includes a very quick and fair peer-review system, which is all easy to use. Visit http://www.dovepress.com/ testimonials.php to read real quotes from published authors. 